\title{
EDITORIAL: \\ JANNE BONDI JOHANNESSEN AND NALS
}

\author{
ØYSTEIN A. VANGSNES \\ UiT The Arctic University of Norway \\ Western Norway University of Applied Sciences
}

On the 15th of June 2020 Professor Janne Bondi Johannessen passed away after having battled cancer for a couple of years. She would have turned 60 only a few weeks later, on the $1^{\text {st }}$ of August.

The NALS Journal was founded by Janne and myself, and it is fair to say that Janne was the driving force behind it. The journal grew out of a specific grant from NOS-HS to the project Nordic Dialect Corpus and Cooperation (NORDiaCORP), funded from 2009 through 2012. This project can best be described as a scheme to consolidate the efforts laid down in the pan-Nordic collaborative Scandinavian Dialect Syntax project (ScanDiaSyn) and the Nordic Center of Excellence in Microcomparative Syntax (NORMS). The scheme also included finalizing the development of the Nordic Dialect Corpus (NDC) and the Nordic Syntax Database (NSD) (see Vangsnes 2007, Johannessen et al. 2009, Lindstad et al. 2009, Vangsnes \& Johannessen 2011, 2019, Johannessen et al. 2012; see also the ScanDiaSyn website at the Text Laboratory, University of Oslo).

One of the goals of the NORDiaCORP project was to develop systematic overviews of the findings established within the existing Nordic research collaboration on dialect syntax/grammar. This goal was met when the first volume of NALS was published in 2014. The volume contained 55 papers on a variety of syntactic and morphosyntactic phenomena that vary across the North Germanic language area. The papers, written by a core group of seven authors, followed a particular format combining data from the NDC corpus (spontaneous speech) and the NSD database (speaker judgments). Janne authored four of the papers and co-authored another two.

The first volume of NALS was published as an electronic atlas on a rather traditional website format. In order to ensure a dynamic continuation of the core idea behind NALS and at the same time give the contributors proper academic credit for their intellectual efforts, we decided early on to turn it into a journal 
and move it to a more feasible platform provided by the University Library at the University of Oslo.

NALS is currently publishing a special issue with papers drawing on the Nordic Word Order Database (NWD) project. An overview paper was published in 2019 , two papers are published in the current volume and additional papers are in the pipeline for 2021. Janne was instrumental in recruiting this series of papers, which is guest edited by Ida Larsson and Björn Lundquist, both of whom were part of the core group writing entries for the first NALS volume.

Janne had a large network of national and international collaborators and she was involved in a variety of scientific projects spanning a wide range of fields from language technology and corpus linguistics to dialectology and theoretical syntax. Volume 11:2 of Oslo Studies in Language is dedicated to her memory. The 29 papers in the volume, written by 49 authors, clearly illustrate Janne's significant position in the field of linguistics, both nationally and internationally.

Although NALS is only a small part of Janne's legacy, the journal was dear to her. My aim is to continue the editorship in her spirit and develop the journal further in line with our goal to draw new isoglosses and bring to the fore novel insights about linguistic phenomena that vary across the North Germanic language area.

\section{REFERENCES}

Lindstad, Arne M., Anders Nøklestad, Janne B. Johannessen, Øystein A. Vangsnes. 2009. The Nordic Dialect Database: Mapping Microsyntactic Variation in the Scandinavian Languages. In K. Jokinen and E. Bick (eds.) NEALT Proceedings Series, Vol. 4, 283-286.

Janne B. Johannessen, Joel Priestley, Kristin Hagen, Tor A. Åfarli, Øystein A. Vangsnes. 2009. The Nordic Dialect Corpus - an Advanced Research Tool. In Kristiina Jokinen and Eckhard Bick (eds.) NEALT Proceedings Series, Vol. 4, 7380.

Johannessen, Janne B, Joel Priestley, Kristin Hagen, Anders Nøklestad \& André Lynum. 2012. The Nordic Dialect Corpus, In Nicoletta Calzolari, Khalid Choukri, Thierry Declerck, Mehmet Ugur Dogan, Bente Maegaard, Joseph Mariani \& Jan Odijk (eds.), Proceedings of the Eighth International Conference on Language Resources and Evaluation, 3388-3391. European Language Resources Association. ISBN 978-2-9517408-7-7.

Vangsnes, Øystein A. 2007. Scandinavian Dialect Syntax (before and after) 2005. In Kristine Bentzen and Øystein A. Vangsnes (eds.) Scandinavian Dialect Syntax 2005, special issue of Nordlyd, 7-24. 
Vangsnes, Øystein A. \& Janne B. Johannessen. 2011. Reconciling corpus and questionnaire data in microcomparative syntax: A case study from Scandinavian. In Frans Gregersen, Jeffrey K. Parrott and Pia Quist (eds.), Language Variation - European Perspectives III, 135-148. John Benjamins. DOI https://doi.org/10.1075/silv.7.11van

Vangsnes, Øystein A. \& Janne B. Johannessen. 2019. The Nordic research infrastructure for syntactic variation: possibilities, limitations and achievements. Glossa: A Journal of General Linguistics, 4(1), $26 . \quad$ DOI: http://doi.org/10.5334/gjgl.708.

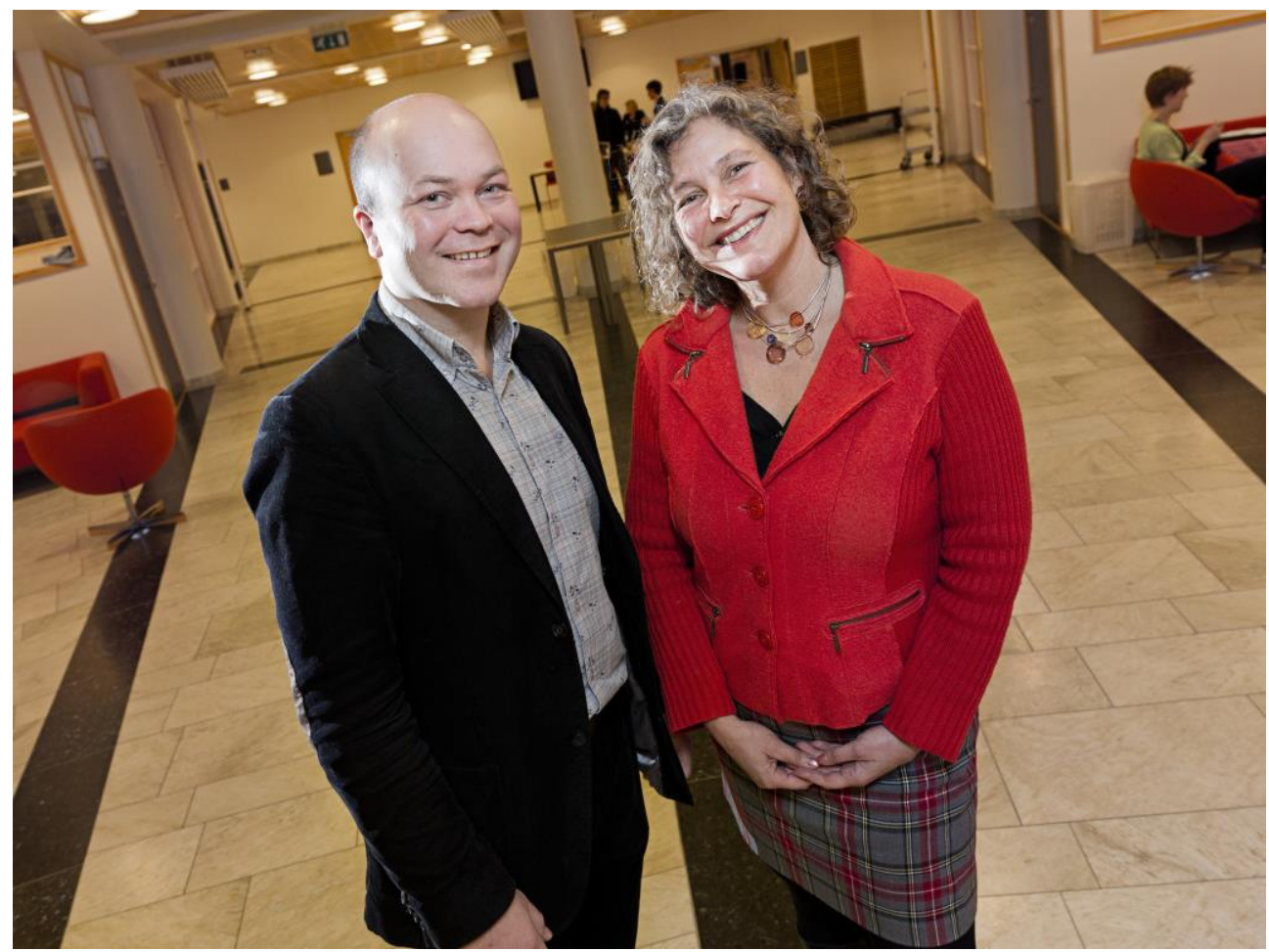

Øystein A. Vangsnes and Janne Bondi Johannessen photographed at the University of Tromsø for a feature article on the Scandinavian dia-lect project, published in Forskerforum 1/2012. (Photo: Ørjan Marakatt Bertelsen) 


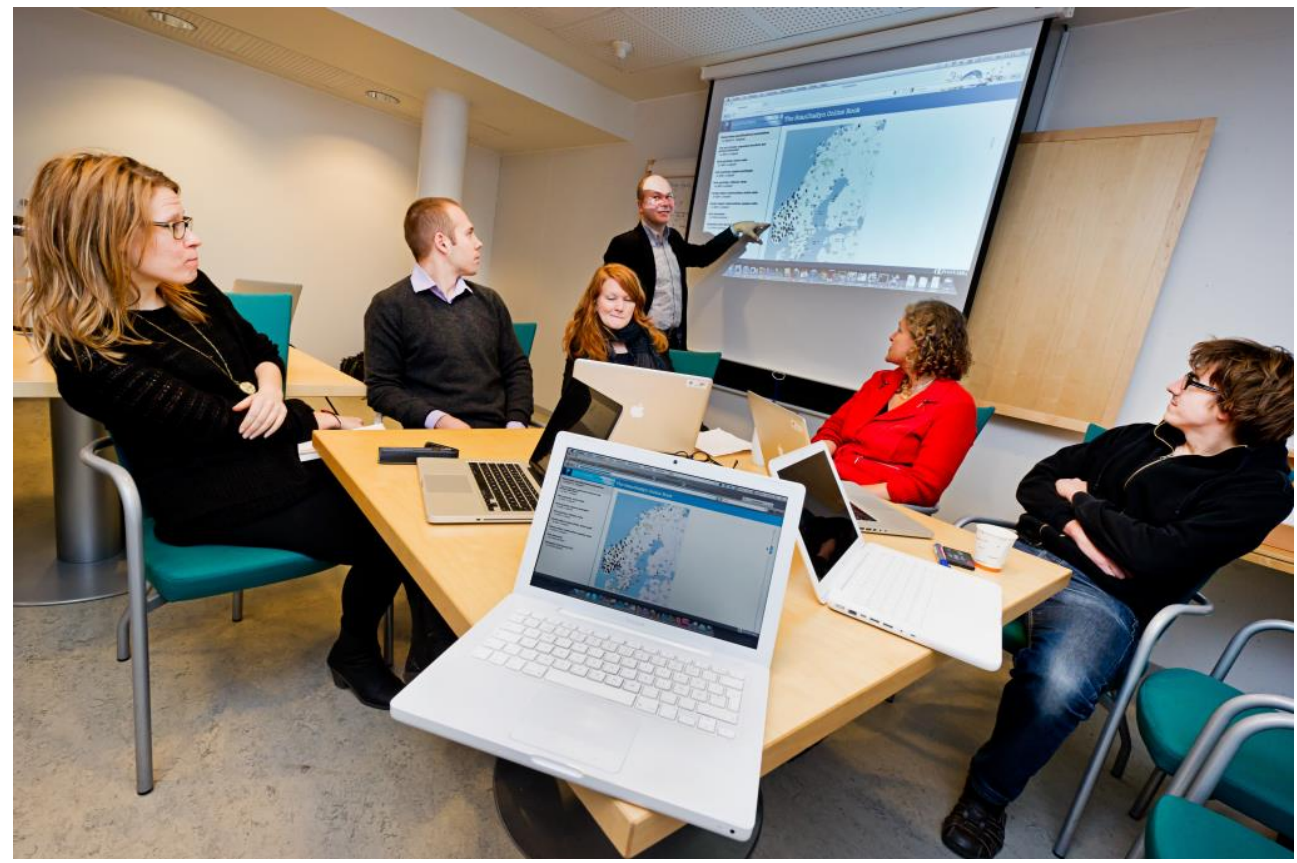

Meeting in the core group of authors for the first volume of NALS at the University of Tromsø in November 2011. From left to right: Ida Larsson, Piotr Garbacz, Kristine Bentzen, Øystein A. Vangsnes, Janne Bondi Johannessen, Björn Lundquist. Originally published in Forskerforum 1/12. (Photo: Ørjan Marakatt Bertelsen) 